\title{
Internato na pandemia Covid-19: a experiência de uma escola médica
}

\author{
Medical internship in the Covid-19 pandemic: the experience of a medical school
}

\author{
Jacqueline Teixeira Caramori ${ }^{1}$ (1) $\mid$ j.caramori@unesp.br \\ Aristides Augusto Palhares Neto ${ }^{1}$ \\ Sumaia Inaty Smaira ${ }^{1}$ \\ aristides.palhares@unesp.br \\ Vanessa dos Santos Silva \\ sumaia.smaira@unesp.br \\ (iD.silva@unesp.br \\ Roberto Antonio de Araújo Costa ${ }^{1}$ \\ roberto.costa@unesp.br \\ Maria Cristina Pereira Lima ${ }^{1}$ \\ maria.cristina@unesp.br
}

\section{RESUMO}

Introdução: A pandemia da Covid-19 provocou milhares de mortes e levou a incontáveis mudanças na forma de organização de serviços de saúde e nas escolas de Medicina mundo afora.

Relato de experiência: Este artigo relata a experiência da Faculdade de Medicina de Botucatu da Universidade Estadual Paulista (Unesp), cujas aulas foram suspensas em função da pandemia.

Discussão: Descrevem-se as motivações para a suspensão e os procedimentos para a retomada das aulas do internato, depois de 15 semanas da interrupção.

Conclusão: Ressalta-se a importância das decisões coletivas, da comunicação empática, do acolhimento e cuidado com a saúde mental e da parceria com o Hospital das Clínicas na realização de rastreamento para a presença do vírus entre os estudantes. Por fim, destaca-se o aprendizado para o professor ao se defrontar, por um lado, com a impotência diante da morte e do desconhecido, e, por outro, com a potência do cuidado que pode ser oferecido em situação tão singular quanto uma pandemia.

Palavras-chave: Covid-19; Internato Médico; Mentoria; Educadores.

\section{ABSTRACT}

Introduction: The COVID-19 pandemic has caused thousands of deaths and led to countless changes in the way health services and medical schools are organized around the world.

Experience report: This article reports on the experience of the Botucatu Faculty of Medicine, UNESP, located in the interior of the state of São Paulo, where classes were suspended due to the pandemic.

Discussion: The reasons for the suspension of internship classes and the procedures for their resumption, after 15 weeks, are described.

Conclusions: The study highlights the importance of collective decisions, empathic communication, mental health care and attention and the partnership with the Hospital das Clínicas in performing track and trace for presence of the virus among the students. Finally, particular emphasis is given to the learning gained by teachers who found themselves feeling, on the one hand, powerless in the face of death and the unknown and, on the other, the strength of the care that can be offered in a situation as unique as the pandemic.

Keywords: Covid-19; Medical Internship; Mentoring; Educators.

1 Universidade Estadual Paulista, Botucatu, São Paulo, Brasil.

Editora-chefe: Daniela Chiesa.

Editora associada: Daniela Chiesa.

Recebido em 05/08/20; Aceito em 28/06/21.

Avaliado pelo processo de double blind review. 


\section{INTRODUÇÃO}

A pandemia da coronavirus disease 2019 (Covid-19) provocou milhares de mortes e inúmeras mudanças na vida de milhões de pessoas em praticamente todos os países. Como ainda não há clareza sobre o quanto vai perdurar o risco de transmissão pelo novo coronavírus ${ }^{1}$, os serviços de saúde tiveram que se reestruturar para atender à demanda já existente e àquela associada à pandemia. Em função dessa mudança na organização dos serviços, muitas escolas médicas tiveram seus cenários totalmente alterados e foram obrigadas a suspender atividades acadêmicas, até mesmo dos alunos dos últimos anos, considerados "quase médicos"2. Se a suspensão de atividades pode enfrentar muitas resistências ${ }^{2}$, o retorno precisa ser ainda mais cuidadoso, pois a pandemia está em evolução, com as estimativas prévias concretizando-se em taxas de mortalidade crescentes.

Este artigo apresenta o processo de retorno dos alunos do internato de uma escola de Medicina. Descreve os procedimentos adotados no cuidado com os alunos e o aprendizado acumulado neste período.

\section{RELATO DE EXPERIÊNCIA}

\section{Contexto}

A Faculdade de Medicina de Botucatu (FMB) é uma das unidades da Universidade Estadual Paulista "Júlio de Mesquita Filho" (Unesp) localizada em Botucatu, cidade com 146 mil habitantes ${ }^{3}$, situada a 235 quilômetros da capital de São Paulo. No ano de 2020, as atividades do internato médico que tiveram seu início em 6 de janeiro foram abruptamente suspensas em 16 de março em função das medidas de enfrentamento da pandemia da Covid-19, determinadas pela universidade e pela superintendência do Hospital das Clínicas da FMB (HCFMB), um dos seus cenários de ensino. Havia, na ocasião, a necessidade de reorganização da assistência prestada pelo HCFMB, que, como um hospital universitário de referência para região centrooeste do estado, foi incorporado ao Plano de Contingência de Combate à Covid-19 pelo governo do estado de São Paulo ${ }^{4}$. Tal medida, associada à necessidade de reorganização também da rede de atenção primária à saúde do município, outro importante cenário de ensino, mudou de forma substancial os cenários de prática, o que comprometeu o ensino. Paralelamente a essa adaptação estrutural da assistência, também havia uma concreta deficiência de equipamentos de proteção individual (EPI), o que não garantia a segurança dos estudantes. Esse foi o contexto que justificou a interrupção, por tempo indeterminado, das atividades presencias nessa escola médica

Como estratégia para manter a conexão entre a instituição e os discentes, foram organizadas e oferecidas atividades teóricas mediadas por tecnologias (ensino remoto), por meio de uma comissão constituída pela direção. Inicialmente, docentes, preceptores e alunos tinham a expectativa de retornar às atividades em curto período de tempo, porém a quarentena da 53a turma de alunos da FMB durou 111 dias. O ensino remoto emergencial foi sendo adaptado com o objetivo de minimizar as perdas e possibilitar, na retomada das atividades, a reorganização dos estágios conforme o estabelecido nas resoluções e medidas publicadas pelo Conselho Estadual de Educação (CEE) $)^{5}$ e pela Pró-Reitoria de Graduação da Unesp (Prograd).

Em junho de 2020, foi divulgado o Plano Geral de Retorno às Atividades da Unesp ${ }^{6}$, dando autonomia e corresponsabilidade para a FMB planejar suas atividades e construir o plano operacional de retomada, desde que acatadas as diretrizes gerais e implementando adaptações em face das peculiaridades locais.

A discussão do retorno passou a ocorrer por fases, que procuraram minimizar os riscos de propagação da doença, ampliar e detalhar as orientações gerais, e seguir os pilares estabelecidos pela universidade, por meio do Comitê Unesp Covid-196. Assim, as ações deveriam ter como base: a defesa da vida, a proteção da saúde e segurança das pessoas, a conservação da capacidade de resposta do sistema de saúde brasileiro e estadual, o papel da Unesp na eliminação da propagação da doença nas comunidades em que está inserida, a minimização de prejuízos às atividades acadêmicas e científicas da instituição e aos membros da comunidade, e a manutenção da excelência da Unesp nas atividades de ensino, pesquisa e extensão.

\section{Preparo para o retorno}

Com o objetivo de garantir um retorno gradual e seguro, foi necessária uma fase de preparação e planejamento. A comunicação com discentes e preceptores de estágios começou com 40 dias de antecedência, tendo como palco os espaços institucionais de discussão do currículo, mas acrescidos de maior participação de discentes e docentes. Nesse momento, o HCFMB já havia reestruturado os cenários de assistência "não Covid", estabelecendo as melhores condições para o retorno das atividades dos alunos dos últimos anos.

Paralelamente, a subcomissão de internato, após amplo debate, elaborou uma proposta de retorno partindo inicialmente do levantamento das condições das unidades, das enfermarias, dos ambulatórios e da rede de atenção primária para que pudessem receber os alunos com segurança e possibilidade de oferecimento de aprendizagem das competências elencadas nos planos de ensino pré-pandemia. O segundo passo foi a garantia com gestores quanto ao fornecimento de EPI, assim como o estabelecimento do fluxo para a retirada deles. 
Finalmente, houve definição da data de reinício das atividades e reorganização do calendário de rodízio dos estágios, com aprovação da redução do número de dias letivos, sem redução da carga horária proposta para cada estágio, conforme estabelecido nas resoluções da universidade e respaldado pelo $\mathrm{CEE}^{5}$. A proposta foi apresentada à Comissão de Internato e ao Conselho de Curso e devidamente aprovada. Nesse contexto, como as atividades teóricas de vários estágios estavam sendo ofertadas em ensino remoto, considerou-se a necessidade de manter o ensino híbrido até o término do curso. Os estágios foram reduzidos em uma semana, o que corresponde aos $20 \%$ da carga teórica máxima preconizada para o período do internato segundo as Diretrizes Curriculares Nacionais $(D C N)^{7}$ e que foi ofertada em ensino remoto.

Outra preocupação da direção da FMB da Unesp foi o levantamento da condição de saúde dos estudantes, durante o afastamento e no momento do retorno, assim como dos que possuíam fatores de risco. Dessa forma, aplicou-se um questionário on-line, previamente ao retorno, antecipando questões da saúde física e mental, sobre acometimentos durante o isolamento ou existência de sintomas relacionados à Covid-19, visando ajudar na adoção das melhores medidas e das recomendações quanto à prevenção e redução de risco de transmissão da doença. Consideraram-se pessoas do grupo de risco: aquelas com doenças cardiovasculares (hipertensão, insuficiência cardíaca, cardiopatia isquêmica, arritmias, doenças cerebrovasculares); pneumopatias graves ou descompensadas; doenças renais crônicas em estágio avançado (graus 3, 4 e 5); diabetes mellitus, conforme juízo clínico; obesidade; transplantes de órgãos; imunossupressão; neoplasias malignas; além de outras a serem redefinidas pelo Ministério da Saúde. A comprovação do grupo de risco se deu por autodeclaração.

\section{Estratégia de acolhimento híbrido}

Respeitando as orientações sanitárias, o acolhimento institucional ocorreu simultaneamente para todos grupos de internato, sendo os alunos acomodados em sete auditórios com devido distanciamento físico. A recepção contou com participação da diretoria da $F M B$, da superintendência do HCFMB, por Google Meet, e dos preceptores e mentores presencialmente, que, além das boas-vindas aos alunos, reforçaram as orientações quanto às estratégias de biossegurança. Em seguida, foi realizada a distribuição de EPI. Seguindo o mesmo protocolo estabelecido pelo HCFMB para os seus profissionais, os estudantes receberam máscaras N95 e foram orientados a usá-las durante todo o tempo de permanência nas enfermarias, nos ambulatórios e em outros ambientes de trabalho. Também foi oferecida uma caixa para acondicionamento durante a alimentação ou higiene pessoal.
Nas unidades básicas de saúde (UBS), os EPI seguiram as orientações locais, e utilizou-se a máscara N95, limitada a situações específicas. Vídeos foram disponibilizados no site institucional para orientar o manejo dos EPI. Estabeleceu-se que os internos deveriam seguir as orientações dos serviços de saúde em que estivessem estagiando, e todo o reinício foi avaliado e discutido com os gestores desses serviços.

\section{Participação de mentores na retomada do internato}

No início de cada ano letivo, os seis grupos de internato, constituídos na média de 15 internos, recebem a designação de um mentor a partir de uma dinâmica de acolhimento. $\mathrm{O}$ mentor é um profissional mais experiente ao qual cabe guiar e aconselhar jovens na formação. $\mathrm{Na} F M B$, estabeleceu-se no internato um mentor por grupo, de modo a estimular o contato frequente entre eles e favorecer o vínculo ${ }^{8}$. A mentoria para o internato tem sido uma estratégia da Comissão de Assuntos Estudantis (CAE) que participa do acolhimento integrado no começo desse ciclo, assumindo o papel de apoio aos estudantes em momentos de conflitos pessoais internos, nas dificuldades e nos enfrentamentos acadêmicos, ou na orientação diante de problemas de saúde física ou sofrimento psíquico.

Desde o momento da interrupção das atividades práticas, durante as discussões sobre ensino remoto e, especialmente, quando houve a mobilização para o retorno presencial, a frequente comunicação foi estimulada entre os mentores, os internos e a gestão. O compartilhamento de situações especiais com a gestão do curso existe de maneira informal por e-mails e grupos de WhatsApp, o que permite rápidos encaminhamentos. Os mentores mantiveram contato, espontaneamente ou sempre que solicitado pela $C A E$, com seus respectivos grupos, com informações para o coletivo ou apoio e busca ativa em situação particular. Com o retorno do internato ao presencial, todos mentores foram mobilizados para garantir a retomada segura de seus grupos. Além disso, estiveram presencialmente no acolhimento, no dia do seu retorno. Também acompanharam a evolução dos estágios, assim como a atenção à saúde dos alunos, atuando na facilitação da comunicação dos internos e mediando o atendimento no âmbito do HCFMB, em caso de suspeita de Covid-19. Aqueles que apresentaram síndrome gripal foram afastados de suas atividades e encaminhados ao atendimento clínico para coleta de amostras de swab nasal e da orofaringe, conforme protocolo estabelecido no HCFMB. Havia uma preocupação por parte dos mentores de que os alunos não comunicassem sintomas leves por receio de serem afastados de suas atividades. Desse modo, realizaram-se um acompanhamento mais próximo e sucessivas orientações sobre os cuidados necessários, tanto individualmente quanto com os colegas de estágio. 


\section{Rastreamento para Sars-CoV-2}

Em consonância com o Plano de Controle da Infecção pela Covid-19 do HCFMB proposto pelo Serviço de Infectologia, pela Comissão de Controle de Infecção Relacionada à Assistência à Saúde e pelo Núcleo de Epidemiologia Hospitalar, a FMB da Unesp ofereceu a testagem para o severe acute respiratory syndrome coronavirus (Sars-CoV-2) em pool de saliva para todos os internos assintomáticos que retornavam às atividades. Com a disponibilidade de maiores informações sobre o novo coronavírus, constatou-se a possibilidade de identificação do vírus em saliva9. Esse rastreamento da presença do vírus em saliva vem sendo conduzido em $100 \%$ dos discentes que retornaram às atividades presenciais e é realizado a cada duas semanas naqueles que se encontram em cenário hospitalar. O rastreamento se justifica para evitar a introdução do vírus nos ambientes hospitalar e universitário, tendo em vista que os discentes deslocam-se por diferentes regiões do estado de São Paulo. Tem sido importante estabelecer uma estratégia de acompanhamento a fim de evitar, tanto quanto possível, a circulação do patógeno no hospital e na universidade com consequente prejuízo a todos os envolvidos (discente, docentes, médicos, pacientes, além do próprio serviço assistencial). É importante destacar que a estratégia proposta não implica o diagnóstico, mas o rastreamento do vírus em pool de saliva, de modo a oferecer segurança à estratégia de retorno. Em caso de detecção do vírus, o aluno deverá ser avaliado pela equipe de saúde responsável pelo ambulatório de diagnóstico.

\section{Vacinação contra COVID 19}

Assim que o Brasil iniciou a vacinação contra Covid 19, em 19 de janeiro, a direção da FMB-UNESP, garantiu a inclusão de seus estudantes de graduação, conforme previsto no Plano Nacional de Imunização, como profissionais de saúde, expostos aos riscos, tanto para aqueles em cenários hospitalares, como na atenção primária à saúde do município de Botucatu.

\section{DISCUSSÃO}

O internato é a etapa que consolida a desenvoltura de habilidades e atitudes esperadas durante a formação médica, e as adaptações devem permitir a continuidade, sem ferir o padrão de qualidade da aprendizagem. Neste momento excepcional, de quarentena e distanciamento social, esse retorno pretende garantir aprendizagens essenciais definidas na proposta pedagógica desse curso de Medicina, restaurar a rotina assistencial e de aprendizado do profissional de saúde em formação, e possibilitar ao estudante participar deste momento histórico com responsabilidade, segurança e serventia.

Ações planejadas têm contribuído para conter o avanço da pandemia em nossa instituição, e o retorno dos estudantes dos últimos anos da graduação aos cenários presenciais está sendo um dos maiores desafios. Apesar das estratégias e das diversas orientações do $\mathrm{CEE}^{5,10}$ e da Unesp ${ }^{6}$, foi necessário discutir a reorganização dos cenários previamente definidos nos planos de ensino, de acordo com a disponibilidade dos serviços, além de elencar novos espaços de prática que tenham condições de oferecer ao aluno a aquisição de habilidades e competências com a segurança necessária. Também foi necessário abrir espaço de discussão para que supervisores de estágios e alunos pudessem avaliar as possibilidades de ajuste e buscar o ponto de equilíbrio entre segurança e aprendizado.

A ansiedade, sentimento mais frequentemente referido pelos alunos quanto ao retorno para atividades presenciais, fez parte de uma pergunta não obrigatória do questionário on-line, sem interesse de pesquisa, que não utilizou o Termo de Consentimento Livre e Esclarecido. O objetivo era obter os norteadores das condições do estado físico e mental dos estudantes (Figura 1). Ansiedade tem sido uma resposta emocional bastante frequente na pandemia, e há autores que a associam ao isolamento experimentado na quarentena. Brooks et al. ${ }^{11}$ conduziram uma revisão dos estudos sobre sintomas mentais relacionados à quarentena. Os autores

Figura 1. Nuvem de palavras mostrando o sentimento manifestado por estudantes do sexto ano de Medicina no retorno às atividades presenciais durante a pandemia da Covid-19 - Faculdade de Medicina de Botucatu.

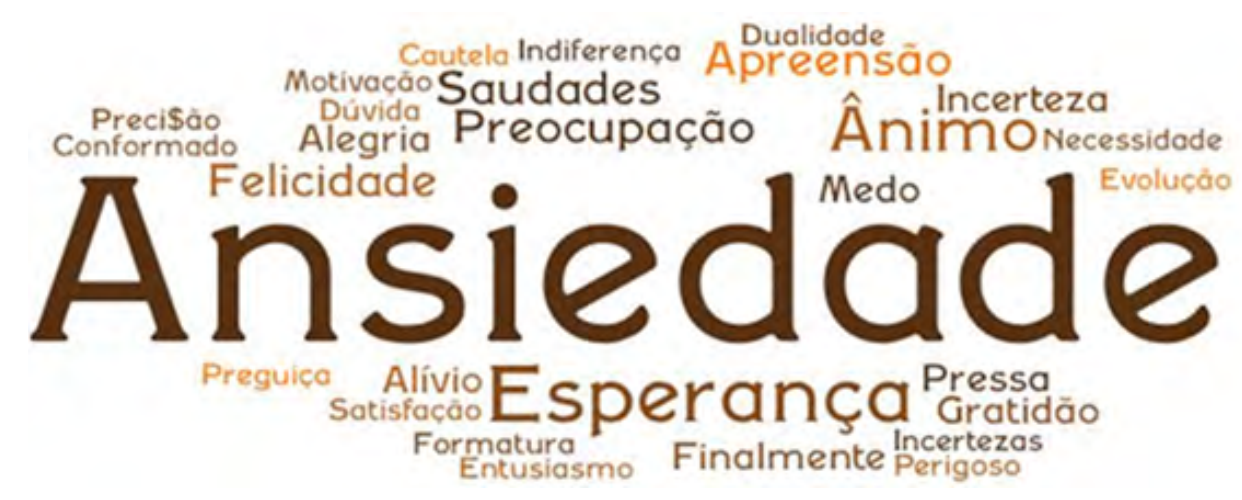


observaram sintomas similares ao transtorno de estresse póstraumático, entre outros. Os estressores incluíam duração maior da quarentena, medo da infecção, tédio, frustrações, perdas financeiras e informação inadequada. Nessa revisão, os autores reforçam o papel-chave que a informação de qualidade e a rápida veiculação ocupam na minimização dos sintomas emocionais. Nesse sentido, a FMB adotou a estratégia de salas para conversa com a turma toda, por meio remoto, ao longo de todo o período - o que, acreditamos, auxiliou os estudantes. Com a presença da direção e dos coordenadores de curso, as salas para conversa foram espaços importantes para acolher as angústias e as dúvidas dos alunos. É necessário mencionar que as informações nem sempre estão disponíveis, nem para os professores, nem para os pesquisadores que estão na linha de frente, em todo o mundo. Mas trabalhamos com a ideia de que é importante responder aos alunos "Não sabemos ainda", quando não há resposta para as perguntas que eles nos trazem. Na verdade, dois dias após a Organização Mundial da Saúde (OMS) estabelecer a condição de pandemia da Covid-19, realizamos uma aula ministrada por um professor de Infectologia, aberta a todos os alunos e professores que pudessem acessar a internet naquele momento. Foi um espaço importante não apenas para dividir as informações disponíveis, mas também compartilhar as dúvidas existentes.

Um outro aspecto que pode intensificar os sintomas mentais, particularmente entre os profissionais de saúde e aqueles que não puderam estar em quarentena, refere-se ao medo da infecção e ao contato com a morte de pacientes. Rolim Neto et al. ${ }^{12}$ discutem esses aspectos e ressaltam que longas jornadas de trabalho, insuficiência de EPI e sobrecarga assistencial são fatores que se somam. O medo de se infectar infelizmente se baseia em fatos reais: os profissionais de saúde são aqueles com maior vulnerabilidade para a infecção. Para que se tenha uma ideia da magnitude, na Itália os profissionais de saúde representaram $8,3 \%$ dos $\operatorname{casos}^{12}$.

Além dos aspectos ressaltados, assegurou-se a qualquer aluno que, caso necessitasse ou desejasse permanecer afastado dos estágios, poderia comunicar-se com a direção e que seria providenciada a suspensão de sua matrícula, podendo retornar assim que se sentisse em condições. Em recente revisão que investigou as mudanças na educação médica em resposta à Covid-19, Gordon et. al. ${ }^{13}$ identificaram uma série de estratégias adotadas nos diferentes países, como alterações do ensino presencial para ensino remoto, treinamento para tratamento da Covid-19, suporte em saúde mental, entre outras. Não identificamos, entre essas atividades, a organização de um rastreamento sistemático como o que está sendo organizado em nossa instituição. É possível que os autores dos artigos revisados não tenham elencado essa estratégia entre as ações relacionadas à educação médica e sim ao cuidado com a saúde. Em nossa experiência, entendemos que participar do rastreamento, como uma ação de autocuidado, faz parte do processo formativo do profissional de saúde.

Um último aspecto que tem sido discutido por diversos estudiosos de políticas públicas refere-se à condução que o governo federal tem adotado no manejo da pandemia ${ }^{14}$. Além disso, é importante destacar que as estratégias implementadas, o negacionismo e as sucessivas trocas de ministros de Saúde têm prejudicado sobremaneira toda a condução do processo. Não é objetivo deste relato avaliar as políticas públicas estabelecidas nos diferentes níveis governamentais e seu impacto sobre a pandemia no país. Contudo, é inegável que as lideranças políticas têm um papel fundamental no sentido de ampliar a compreensão das suas comunidades sobre a Covid-19, e essa maior ou menor condição vai impactar profundamente o Sistema Único de Saúde e as instituições de ensino que formam esses profissionais.

\section{CONCLUSÃO}

Para finalizar, é preciso reforçar que não se pretende neste relato de experiência avaliar as medidas tomadas, mas sim refletir sobre o que aprendemos nesse processo. No momento em que finalizamos este relato, o país contabilizou mais de 541 mil mortos pela Covid-19 e mais de 19 milhões de brasileiros e brasileiras infectados. Do mesmo modo que cada uma dessas pessoas possui uma história, uma singularidade, (re) aprendemos que cada aluno, cada profissional, cada professor é singular e tem uma dúvida, uma angústia ou contribuição a dar ao grupo. Ampliar os espaços de escuta e acolhimento tem sido fundamental para que isso ocorra de forma mais efetiva e empática. Tomar as decisões de forma colegiada tem auxiliado os gestores acadêmicos e envolvido a comunidade - sem a qual as decisões correriam o risco de tornar-se letras mortas no papel. É possível que, ao nos colocarmos como "não sabedores" de toda verdade, sobre o vírus, por exemplo, tenhamos estabelecido modelos de profissionais que não temem assumir a própria ignorância e se comprometem com a aprendizagem como um processo contínuo e necessário ao perfil profissional previsto pelas DCN.

Enfim, nesse processo, estamos aprendendo sobre temas muitos caros à educação médica ou nos lembrando deles, como a fortaleza do trabalho em equipe, a necessidade da comunicação empática, a impotência diante da morte, mas, ao mesmo tempo, a potência do cuidado até que ela ocorra, e a necessidade de admitirmos nosso "não saber" para então partirmos em busca das respostas. E talvez o mais importante é que acreditamos que nossos alunos estão caminhando ao nosso lado nesta pandemia. 


\section{AGRADECIMENTOS}

Agradecemos às áreas de apoio da FMB - técnica acadêmica, administrativa, técnica de informática e de serviços - a impecável organização de EPI, auditórios e suporte virtual. A todos os preceptores e mentores. Agradecemos ao Laboratório de Biologia Molecular e aos professores de Infectologia com programa de rastreamento, aplicativo de sintomas, atendimento e monitoramento dos estudantes. Por fim, somos gratos aos representantes dos estudantes que mantem protagonismo em todas etapas.

\section{CONTRIBUIÇÃO DOS AUTORES}

Todos os autores atuaram no planejamento das ações desenvolvidas e colaboraram integralmente na redação deste relato de experiência, aprovando a versão final do manuscrito.

\section{CONFLITO DE INTERESSES}

Declaramos não haver conflito de interesses.

\section{FINANCIAMENTO}

Declaramos não haver financiamento.

\section{REFERÊNCIAS}

1. Kissler SM, Tedijanto C, Goldstein E, Grad YH, Lipstich M. Projecting the transmission dynamics of Sars-CoV-2 through the postpandemic period. Science. 2020;368:860-8.

2. Machado MBSD. On the frontlines, behind the computer screen. Acad Med. 2020;95(11):e10-e11. doi 10.1097/ACM.0000000000003601.

3. Instituto Brasileiro de Geografia e Estatística. Cidades e estados: Botucatu [acesso em 4 ago 2020]. Disponível em: https://www.ibge.gov.br/cidadese-estados/sp/botucatu.html.
4. Hospital das Clínicas da Faculdade de Medicina de Botucatu. Centro de Contingência do Estado de São Paulo. São Paulo: Secretaria de Estado da Saúde de São Paulo; 13 mar 2020 [acesso em 19 jul 2020]. Disponível em: https://www.hcfmb.unesp.br/hcfmb-integra-centro-de-contingencia-docovid-19-no-estado-de-sao-paulo/.

5. São Paulo. Resolução Seduc, de 18 de março de 2020. Diário Oficial do Estado, 19 mar 2020. Seção I, p. 18 [acesso em 4 ago 2020]. Disponível em: https://decentro.educacao.sp.gov.br/resolucao-seduc-de-18-3-2020/

6. Plano Geral de Retorno às Atividades da Unesp. São Paulo: Comitê Covid Unesp; 15 jun 2020 [acesso em 19 jul 2020]. Disponível em: https://www2. unesp.br/Modulos/Noticias/35833/retomadaplanorevisado.pdf.

7. Brasil. Resolução no 3, de 20 de junho de 2014. Institui Diretrizes Curriculares Nacionais do curso de Graduação em Medicina e dá outras providências. Diário Oficial da União; 23 jun 2014. Seção 1, p. 8-11.

8. Botti SHO, Rego S. Preceptor, supervisor, tutor e mentor: quais são seus papéis? Rev Bras Educ Med. 2008;32(3):363-73. doi: 10.1590/S010055022008000300011

9. Kelvin KWT, Owen TYT, Wai-Shing L, Anthony RT, Tak-Chiu W, David CL, et al. Temporal profiles of viral load in posterior oropharyngeal saliva samples and serum antibody responses during infection by Sars-CoV-2: an observational cohort study. Lancet Infect Dis. 2020;20(5):565-74. doi: 10.1016/S1473-3099(20)30196-1.

10. São Paulo. Resolução SEE, de 20 de julho de 2020. Diário Oficial do Estado; 22 jul 2020. Seção l, p. 23 [acesso em 4 ago 2020]. Disponível em: http:// www.ceesp.sp.gov.br/ceesp/textos/2020/740998-19-Delib-185-20Indic-196-20.pdf.

11. Brooks SK, Webster RK, Smith LE, Woodland L, Wessely S, Greenberg N, et al. The psychological impact of quarantine and how to reduce it: rapid review of the evidence. Lancet. 2020; 395(10227):912-20.

12. Rolim Neto ML, Almeida HG, Esmeraldo JD, Nobre CB, Pinheiro WR, de Oliveira CRT, et al. When health professionals look death in the eye: the mental health of professionals who deal daily with the 2019 coronavirus outbreak. Psychiatry Res. 2020;288:112972. doi: 10.1016/j. psychres.2020.112972.

13. Gordon $M$, Patricio $M$, Horne $L$, Muston A, Alston SR, Pammi $M$, et al. Developments in medical education in response to the Covid-19 pandemic: a rapid BEME systematic review: BEME Guide n ${ }^{\circ} 63$. Med Teach. 2020;42(11):1202-15. doi: 10.1080/0142159X.2020.1807484.

14. Dall'Alba R, Rocha CF, Silveira RP, Dresch LSC, Vieira LA, Germanò MA. Covid-19 in Brazil: far beyond biopolitics. Lancet, 2021;397:579-80. 